\title{
Co-existence of Overweight/obesity and Stunting: It's Prevalence and Associated Factors Among Under - Five Children in Addis Ababa, Ethiopia
}

Sindew Ahmed ( $\sim$ hayatlove2005@gmail.com )

Kotebe Metropolitan University

\section{ALEM SEBSBIE}

Kotebe Metropolitan University

ABEBE MINDA

Kotebe Metropolitan University

Research Article

Keywords: Children under-five, Double burden, Ethiopia, Overweight/obesity, Stunting

Posted Date: January 19th, 2022

DOI: https://doi.org/10.21203/rs.3.rs-1219464/v1

License: (1) This work is licensed under a Creative Commons Attribution 4.0 International License. Read Full License 


\section{Abstract}

Background: Double burden of malnutrition is a global problem posing a serious public health challenge especially in low- and middle-income countries including Ethiopia, where high prevalence of under-nutrition continues to exist and overweight is increasing at an alarming rate. Although both under-nutrition and over-nutrition are investigated extensively in Ethiopia, evidences about double burden of malnutrition especially at individual level are very limited.

Objective: To assess the prevalence of the co-existence of overweight/obesity and stunting and associated factors among underfive children in Addis Ababa, Ethiopia.

Methods: Institution based cross-sectional study was conducted from May to June, 2021 among 422 mothers to child pairs in Addis Ababa. Twenty nine (30\%) of the health centers in Addis Ababa were selected to take part in the study using simple random sampling technique. The total sample size was allocated proportionally to each of the selected health centers based on their performances within six months prior to the study. Systematic random sampling method was used to select the study participants. An interviewer-administered structured questionnaire was used to collect data. Descriptive statistics and hierarchical logistic regression model were used to characterize the study population and to identify factors that are associated with the outcome variable respectively. Odds ratio along with $95 \% \mathrm{Cl}$ were estimated to measure the strength of the association. Level of statistical significance was declared at $p$ value less than 0.05 .

Results: The prevalence of the co-existence of overweight/obesity and stunting was $5.1 \%$ with $95 \% \mathrm{Cl}(2.9 \%-7.1 \%)$. The hierarchical logistic regression analysis revealed that child age (6 -23 months) [(AOR $=2.86,95 \%$ Cl: (1.02 - 8.04)], maternal education status (non-educated) [(AOR $=4.98,95 \% \mathrm{Cl}$ : $(1.33-18.66)]$, maternal age during birth $(\geq 28$ years) [(AOR $=0.22,95 \% \mathrm{Cl}$ : $(0.06-0.79)]$ and child birth order $\left(3^{+}\right)[(A O R=6.38,95 \% \mathrm{Cl}:(1.03-39.7)]$ were significantly associated with the co-existence of overweight /obesity and stunting.

Conclusion and recommendations: The study revealed that the prevalence of the co-existence of overweight/obesity and stunting is low in Ethiopia. However, local and national nutrition policies and programs should be tailored and implemented to simultaneously address both under-nutrition and over-nutrition.

\section{Introduction}

The double burden of malnutrition (DBM) is defined as the co-occurrence of under-nutrition along with over-nutrition or diet related non communicable diseases (NCDs) (1-4). This co-occurrence or simultaneous existence of under-nutrition (predominately stunting) and over-nutrition (overweight/obesity) is also termed as nutritional dual-burden (5). It can occur at population, household and individual levels (5-7).

The DBM is a global problem posing a serious public health challenge especially in low- and middle-income countries (LMIC), where high prevalence of under-nutrition continues to exist and overweight is increasing at an alarming rate $(1,8-11)$.

According to the global nutrition report for the year 2018, the prevalence of the co-existence of overweight and stunting among under-five children is $1.87 \%$ ( 8.23 million) globally. The magnitude of the coexistence of overweight/obesity and stunting is $2.7 \%$ in Europe, $2.3 \%$ in Africa and $0.8 \%$ in the Americas (12).

Evidence have indicated that DBM is more prevalent in urban areas and it is a concern particularly for countries having a high prevalence rate of stunting $(13,14)$. It particularly affects the urban poor, the rural rich and people living in slum areas (15). Children aged below five years are also the most susceptible age group to DBM (6).

Sub-Saharan Africa (sSA) is suffering with the DBM with high magnitude of under-nutrition and an increasing burden of overweight/obesity and diet-related NCDs (16). Ethiopia is not an exception since, the country is undergoing nutrition transition as a result of economic growth and urbanization, which could led to rise in the magnitude of DBM (17). In Ethiopia, malnutrition has been declining over the last two decades as a result of the implementation of both nutrition specific interventions and nutrition sensitive interventions guided by the National Nutrition Programs (NNP I \& NNP II) (18). However, the problem of under nutrition particularly stunting remains as a major public health problem in Ethiopia and simultaneously the magnitude of overweight and 
obesity is increasing rapidly especially in urban areas (19-21). The problem of childhood obesity in Ethiopia is not recognized as a serious problem and lacks adequate attention (22).

The study setting, Addis Ababa, is the capital city of Ethiopia and it is the biggest and most rapidly growing city where $25 \%$ of the country's urban population lives (23). Although the prevalence of stunting is lower in Addis Ababa compared to the other regions of Ethiopia, still $19.6 \%$ of under-five children are suffering with stunting and $11.4 \%$ with overweight/obesity (24). Evidence regarding DBM in Ethiopia is very scarce especially at individual level and particularly in children. Most of the studies are concentrated in investigating under-nutrition and overweight/obesity independently. Therefore, this study was aimed to assess the co-existence of overweight/obesity and stunting and associated factors among children aged 6-59 months.

\section{Methods}

\section{Study area}

The research was carried out in Addis Ababa, Ethiopia's capital and largest city. Addis Ababa is a chartered city with three levels of authority: city government at the top, 11 sub-cities in the middle, and 126 woredas at the bottom. The total population of the city for the year 2020 was estimated to be 4,793,699 (25). According to Addis Ababa health bureau, the number of under-five children in 2021 was 342,989 and 304,879 (6.4\%) of them were children between 6 and 59 months of age. In the city, six governmental hospitals and 98 health centers are providing comprehensive health care services to the population of the city.

\section{Study design and period}

An institution based cross-sectional study design was conducted from May to June, 2021.

\section{Study population}

All children aged 6 to 59 months with their respective mothers/care givers who were residing in Addis Ababa, Ethiopia was the source population. The study population was all randomly selected children aged 6 to 59 months with their respective mothers/caregivers who visited public health centers for growth monitoring and promotion services, vaccination services, Vitamin A supplementation, deworming and under-five outpatient department (OPD) in Addis Ababa during the study period.

\section{Sample size determination}

Sample size was determined based on a single population proportion formula assuming, proportion ( $P=50 \%)$ because of lack of evidence in Ethiopia, confidence level (95\%) and margin of error (5\%), the minimum required sample size was 384 . Adding $10 \%$ for non-response rate, the final sample size was 422.

\section{Sampling procedure}

Simple random sampling method was employed among 98 health centers to select $29(30 \%)$ of the health centers. Then the final sample size was allocated proportionally to each of randomly selected health centers based on their performances (daily average number of under-five children who have been coming to the health center seeking health care services). Systematic sampling method was used to select study participants (mother to child pairs) from each of randomly selected health centers within the predetermined study period.

\section{Data collection procedures}

Data were collected using interviewer administered questionnaire which was adapted from various similar studies $(17,26-32)$ from mothers / caregivers of children aged 6 to 59 months. Six B.Sc. holder health professionals (four data collectors and two supervisors) who had experience in data collection and supervision were recruited and deployed to collect data and supervise the process. Prior to data collection, the data collectors and supervisors received three days theoretical and practical training on the study.

\section{Anthropometric measurement}




\section{Height}

Height/length measurements were carried out with standard measuring boards to the nearest $0.1 \mathrm{~cm}$. Children under the age of 24 months were measured in lying down (recumbent) position on the board, while children aged 24 to 59 months were measured in a standing-up position. Mothers were requested to remove their children's shoes, hair ornaments and other things that interfere in the measurement of the length/height of the child (33).

\section{Weight}

Weight of infants was measured using a Salter spring scale while young children using digital beam balance with a minimum cloth and barefoot to the nearest of $0.1 \mathrm{~kg}$. Weighting scales were calibrated regularly. Height for age Z score (HAZ) and weight for height Z score (WHZ) were determined using WHO Anthro software version 3.1.0.

\section{Wealth Index}

Wealth index was calculated using principal component analysis (PCA). Mothers were asked questions about their household fixed assets and housing condition adapted from the Ethiopian demographic and health survey report (EDHS-2016) (34).

\section{Data management analysis}

Data were entered in to Epi-Info version 7.2 Software. Then data were exported into statistical software package for social sciences (SPSS) version 20 for analysis after performing data cleaning. Descriptive statistics were computed to summarize and describe the data. Binary logistic regression model was fitted to identify factors associated with the outcome variable. Variables with the result of p-value of less than 0.25 in the bi-variable analysis were entered in to the multivariable analysis (hierarchical logistic regression model). Crude odds ratio (COR) and adjusted odds ratio (AOR) using $95 \%$ confidence interval were computed to see the strength of associations. A p - value of less than 0.05 in the hierarchical logistic regression analysis was used to declare statistical significance.

\section{Data quality management}

To ensure data quality, experienced data collectors and supervisors were recruited, deployed and trained. Furthermore, pre-testing of the questionnaire was carried out. The data collectors were also supervised and provided onsite technical assistance both by the supervisors and the principal investigator to assure the quality of data. In addition to this, data completeness and consistency were checked on daily basis and corrective measures were taken timely. Moreover, measurement equipment was calibrated regularly before starting the anthropometric measurements. After data collection, each questionnaire was coded and checked for completeness and consistency prior to data entry. Checking of data for missed values, inconsistencies and outliers were also done after data entry in to EPI-Info version 7.2 and after exporting into SPPS version 20.

\section{Variable measurement}

\section{Outcome variable}

The outcome variable was co-existence of overweight/obesity and stunting which is defined as the existence of both overweight/obesity (WHZ score > +2 SD) and stunting (HAZ score of <-2 SD) with in the same child. It was dichotomized in to coexistence of overweight/obesity and stunting as "Yes" or "No".

\section{Exposure variables}

The predictor variables were categorized into child characteristics, distal factors, intermediate factors and proximal factors. The child characteristics include child age and child sex. The distal factors were maternal education, maternal occupation, father's education, and head of the household and house hold wealth index category.

The Intermediate factors were marital status; family size, number of under- 5 children, maternal age at child birth, and type of family, availability of health insurance, child birth order, and child ever received any vaccinations and type of latrine 
The proximal factors were weight of the child at birth, child ever breast fed, time of initiation of breast feeding, duration of breast feeding, age initiated for complementary feeding (CF), diarrhea in the previous 2 weeks, cough in the previous 2 weeks, fever in the previous 2 weeks, vitamin A dose supplementation within last 6 months, and child dewormed within the last 6 months

\section{Results}

A total of 411 mothers and children were participated in the study with a response rate of $97.4 \%$.

\section{Socio - demographic characteristics of respondents}

The mean $( \pm S D)$ age of the children was 2.28 years with $( \pm 1.18)$. Two hundred thirty $(56 \%)$ of the children were male. The majority (87.4\%) and (46\%) of the mothers attended formal education and were housewives respectively. (Table 1 )

Table 1

Socio - demographic characteristics of respondents, Addis Ababa, Ethiopia 2021

\begin{tabular}{|llll|}
\hline Variables & Category & Frequency & Percent \\
\hline Child sex & Male & 230 & 56 \\
\hline Child age in months & Female & 181 & 44 \\
\hline & $12-23$ & 63 & 15.3 \\
\hline & $24-35$ & 124 & 30.2 \\
\hline & $36-47$ & 109 & 26.5 \\
\hline & $48-59$ & 72 & 17.5 \\
\hline Maternal education & No education & 43 & 10.5 \\
\hline & Primary school & 52 & 12.6 \\
\hline & Secondary school & 115 & 28.0 \\
\hline & Diploma & 108 & 26.3 \\
\hline & Degree \& above & 54 & 20.0 \\
\hline & Housewife & 189 & 13.1 \\
\hline Government employee & 82 & 20.0 \\
\hline Maternal occupation & 31 & 7.5 \\
\hline & Merchant & 36 & 8.8 \\
\hline & Non-government employee & 30 & 17 \\
\hline & Self-employee & - \\
\hline & Others & 36 & 20.0 \\
\hline
\end{tabular}


Table 1

Continued

\begin{tabular}{|llll|}
\hline Variables & Category & Frequency & Percent \\
\hline Fathers education & No education & 20 & 4.8 \\
& Primary school & 57 & 13.9 \\
& Secondary school & 168 & 40.9 \\
& Diploma & 71 & 17.3 \\
\hline Head of the household & Fegree \& above & 95 & 23.1 \\
& Mother & 196 & 47.7 \\
& Both & 18 & 4.4 \\
\hline Wealth index & Lowest & 197 & 47.9 \\
\hline & Second & 82 & 20.2 \\
\hline & Middle & 82 & 20.0 \\
\hline & Fourth & 85 & 20.7 \\
\hline Highest & 79 & 19.2 \\
\hline
\end{tabular}

\section{Magnitude of the co-existence of overweight/obesity and stunting}

According to the study, the magnitude of the co-existence of overweight/obesity and stunting was $5.1 \%$ with $95 \% \mathrm{Cl}(2.9 \%-7.1 \%)$. (Figure 1)

\section{Intermediate factors associated with the co-existence of overweight/obesity and stunting}

Environmental factors associated with the co-existence of overweight/obesity and stunting

Half (50.4\%) of the respondents had improved sanitation facility. Most (79.3\%) of under - five children participated in the study were living with nuclear family. Almost two-third (64.7\%) of the respondents had a family size of 4 and above. (Table 2)

Table 2

Environmental factors associated with the co-existence of overweight/obesity and stunting in under-five children in Addis Ababa, Ethiopia 2021

\begin{tabular}{|llll|}
\hline Variables & Category & Frequency & Percent \\
\hline Type of latrine & Improved & 207 & 50.4 \\
\hline Type of family & Unimproved & 204 & 49.6 \\
\hline Family size & Nuclear family & 326 & 79.3 \\
\hline \multirow{2}{*}{ No of under - five children in the $\mathrm{HH}$} & 1 & 85 & 20.7 \\
\cline { 2 - 4 } & 2 & 145 & 35.3 \\
\hline & 2 & 266 & 64.7 \\
\hline & $3^{+}$ & 274 & 66.7 \\
\hline
\end{tabular}


The majority (92.5\%) and (64.7\%) of the respondents were married and in age group between 20 to 29 years. Only 123 (30\%) of the respondents had health insurance at household level. (Table 3)

Table 3

Maternal factors associated with the co-existence of overweight/obesity and stunting among under-five children in Addis Ababa, Ethiopia 2021

\begin{tabular}{|c|c|c|c|}
\hline Variables & Category & Frequency & Percent \\
\hline \multirow[t]{5}{*}{ Marital status } & Married & 380 & 92.5 \\
\hline & Single & 11 & 2.7 \\
\hline & Separated & 10 & 2.4 \\
\hline & Widowed & 5 & 1.2 \\
\hline & Divorced & 5 & 1.2 \\
\hline \multirow[t]{3}{*}{ Maternal age at child birth } & $<20$ & 15 & 3.7 \\
\hline & $20-29$ & 266 & 64.7 \\
\hline & $30-39$ & 130 & 31.6 \\
\hline \multirow[t]{3}{*}{ Birth order of the child } & 1 & 189 & 46.0 \\
\hline & 2 & 159 & 38.7 \\
\hline & $3^{+}$ & 63 & 15.3 \\
\hline \multirow[t]{2}{*}{ Child ever Vaccinated } & Yes & 411 & 100 \\
\hline & No & 0 & - \\
\hline \multirow[t]{3}{*}{ Immunization status of the child } & Fully immunized & 251 & 61.1 \\
\hline & Currently on follow up & 146 & 35.5 \\
\hline & Not fully immunized & 14 & 3.4 \\
\hline \multirow[t]{2}{*}{ Availability of Health insurance at $\mathrm{HH}$ level } & Yes & 123 & 29.9 \\
\hline & No & 288 & 70.1 \\
\hline
\end{tabular}

\section{Proximal factors associated with the co-existence of overweight/obesity and stunting}

Individual level factors associated with the co-existence of overweight/obesity and stunting

Three hundred fifty four $(86.1 \%)$ children had average birth weight $(2.5-4 \mathrm{~kg})$. More than half $(53.3 \%)$ of the respondents had breast fed their child for $12-24$ months. Two hundred fifty nine $(63 \%)$ of the mothers started complementary feeding at six month for their children. Only 183 (44.5\%) of children had dewormed in the previous six months prior to the data collection. (Table 4) 
Table 4

Proximal factors associated with the co-existence of overweight/obesity and stunting among under - five children in Addis Ababa, Ethiopia 2021

\begin{tabular}{|c|c|c|c|}
\hline Variables & Category & Frequency & Percent \\
\hline \multirow[t]{3}{*}{ Birth weight } & $<2.5 \mathrm{~kg}$ & 35 & 8.5 \\
\hline & $2.5-4 \mathrm{~kg}$ & 354 & 86.1 \\
\hline & $>4 \mathrm{~kg}$ & 22 & 5.4 \\
\hline \multirow[t]{2}{*}{ Child ever been breastfed } & Yes & 405 & 98.5 \\
\hline & No & 6 & 1.5 \\
\hline \multirow[t]{3}{*}{ Time of initiation of breast feeding } & Within one hour & 284 & 69.1 \\
\hline & Within the first 24 hours & 102 & 24.8 \\
\hline & $>24$ hours & 25 & 6.1 \\
\hline \multirow[t]{3}{*}{ Duration of breast feeding } & $<12$ months & 147 & 35.8 \\
\hline & $12-24$ months & 219 & 53.3 \\
\hline & $>24$ months & 45 & 10.9 \\
\hline \multirow[t]{3}{*}{ Age initiated for CF } & Before 6 months & 123 & 29.9 \\
\hline & At 6 month & 259 & 63.0 \\
\hline & After 6 months & 29 & 7.1 \\
\hline \multirow[t]{2}{*}{ Diarrhea in the previous 2 weeks } & Yes & 74 & 18.0 \\
\hline & No & 337 & 82.0 \\
\hline \multirow[t]{2}{*}{ Cough in the previous 2 weeks } & Yes & 82 & 20.0 \\
\hline & No & 329 & 80.0 \\
\hline \multirow[t]{2}{*}{ Fever in the previous 2 weeks } & Yes & 94 & 22.9 \\
\hline & No & 317 & 77.1 \\
\hline \multirow[t]{2}{*}{ Vitamin A supplement } & Yes & 337 & 82.0 \\
\hline & No & 74 & 18.0 \\
\hline \multirow[t]{2}{*}{ Deworming } & Yes & 183 & 44.5 \\
\hline & No & 228 & 55.5 \\
\hline
\end{tabular}

\section{Factors associated with the co-existence of overweight/obesity and stunting}

\section{Results of bi-variable Analysis}

Thirteen variables, child age, maternal education, maternal occupation and level of father's education among the distal factors, family size, maternal age at child birth, birth order and availability of health insurance from intermediate factors, and birth weight, duration of breast feeding, age initiated for complementary feeding, vitamin A supplement and deworming in the previous 6 months from the proximal factors had p-value less than $0.25(p<0.25)$ with the co-existence of overweight/obesity and stunting in the bi-variable analysis and were candidates for the multivariable analysis.

\section{Results of multivariable analysis}


Three step wise models in the hierarchical logistic regression analysis were used to identify factors associated with the coexistence of overweight/obesity and stunting. In model one distal factor were entered to estimate their effect on the outcome variable. Model two revealed the relationship among distal factors, intermediate factors and the co-existence of overweight/obesity and stunting. Model three was used to evaluate the combined effects of distal, intermediate and proximal factors on the outcome variable. Child characteristics (age and sex) are retained in all the three models.

In model one, child age [(AOR = 3.38, (95\% Cl: $(1.26$ - 9.09)] and maternal education [(AOR $=5.73,95 \% \mathrm{Cl}:(1.78-18.43)]$ were significantly associated with the co-existence of overweight/obesity and stunting. In model two (after the addition of intermediate factors $)$ child age [(AOR $=2.86,95 \% \mathrm{Cl}$ : $(1.02-8.04)]$, maternal education [(AOR $=5.18,95 \% \mathrm{Cl}:(1.51-17.76)]$ and maternal age during birth $[(A O R=0.26,95 \% \mathrm{Cl}$ : $(0.08-0.87)]$ revealed significant association. In the final model (after the addition of proximal factors in model three), maternal education [(AOR $=4.9895 \% \mathrm{Cl}$ : $(1.33-18.66)]$, maternal age during birth [(AOR $=0.22,95 \% \mathrm{Cl}$ : $(0.06-0.79)]$ and birth order of the child $[(A O R=6.38,95 \% \mathrm{Cl}$ : $(1.03-39.7)]$ were significantly associated with the co-existence of overweight/obesity and stunting. (Table 5).

Table 5

Bi-variable and multivariable analysis of factors associated with the co-existence of stunting and overweight/obesity among under- five children in Addis Ababa, Ethiopia 2021.

\begin{tabular}{|c|c|c|c|c|c|c|}
\hline \multirow[t]{2}{*}{ Variables } & \multicolumn{2}{|c|}{ CEOS } & \multirow[t]{2}{*}{ COR $(95 \% \mathrm{Cl})$} & \multicolumn{3}{|l|}{ AOR (95\% Cl) } \\
\hline & Yes & No & & Model 1 & Model 2 & Model 3 \\
\hline \multicolumn{7}{|c|}{ Child age in months } \\
\hline $6-23$ & 15 & 172 & $3.17(1.20,8.34)^{\star}$ & $3.38(1.26,9.09)^{\star}$ & $2.86(1.02,8.04)^{\star}$ & $1.69(0.48,6.05)$ \\
\hline $24-59$ & 6 & 218 & Ref. & Ref. & Ref. & Ref. \\
\hline \multicolumn{7}{|c|}{ Maternal education } \\
\hline Non - educated & 7 & 45 & $3.83(1.47,10)^{\star}$ & $\begin{array}{l}5.73(1.78 \\
18.43)^{\star}\end{array}$ & $\begin{array}{l}5.18(1.51 \\
17.76)^{\star}\end{array}$ & $\begin{array}{l}4.98(1.33 \\
18.66)^{\star}\end{array}$ \\
\hline Educated & 14 & 345 & Ref. & Ref. & Ref. & Ref. \\
\hline \multicolumn{7}{|l|}{ Birth order } \\
\hline 1 & 14 & 175 & Ref. & & Ref. & Ref. \\
\hline 2 & 3 & 156 & $\begin{array}{l}0.240(068 \\
0.852)^{\star}\end{array}$ & NA & $0.98(0.18,5.31)$ & $0.89(0.16,5.03)$ \\
\hline $3^{+}$ & 4 & 59 & $0.847(0.268,2.68)$ & NA & $4.82(0.84,27.82)$ & $6.38(1.03,39.7)^{\star}$ \\
\hline \multicolumn{7}{|c|}{$\begin{array}{l}\text { Maternal age during } \\
\text { birth }\end{array}$} \\
\hline$<28$ & 16 & 178 & Ref. & & Ref. & Ref. \\
\hline$\geq 28$ & 5 & 212 & $0.262(0.09,0.73)^{*}$ & NA & $0.26(0.08,0.87)^{\star}$ & $0.22(0.06,0.79)^{*}$ \\
\hline
\end{tabular}

Ref. = Reference

NA - not applicable

* - Significant at $p$ value $<0.05$

\section{Discussion}

The study revealed that magnitude of the co-existence of overweight/obesity and stunting among under-five children was $5.1 \%$ : showing that Ethiopia is experiencing the double burden of malnutrition at individual level. The finding is comparable with a study conducted in Mexico (5\%) and India (5.4\%) $(29,35)$. But it is higher than studies conducted in Kenya (1\%), South Africa 
(1.2\%),Vietnam (1.4\%), Bolivia (2.3\%), Thailand (1.3\%) and Colombia $(0.1 \%)(13,27,28,36-38)$. The possible reason for this might be high prevalence rate of stunting in Ethiopia (19). This is because countries having higher magnitude of under-nutrition are more at risk for an increased prevalence of obesity $(31,39)$. However the result is lower than findings from Egypt $(10.9 \%)$, Ghana (19\%) and Mexico $(10.3 \%)(8,29,32)$. The possible reason for this may be the difference in socio-economic status, urbanization and the stage of nutrition transition among countries. The difference in study period and sample size might be also another possible reasons for the discrepancies in the prevalence of CEOS across countries.

The study showed that child age is significantly associated with the co-existence of overweight/obesity and stunting in model two. The odd of the co-existence of overweight/obesity and stunting among children aged 6-23 months was 2.86 times higher than that of children aged 24-59 months. This finding is in line with a study conducted in Indonesia and Papua New Guinea $(31,40)$. The possible reason could be due to feeding practices of the mother/caretaker within the first 1000 days of life. Malnutrition in children is associated with poor breastfeeding practice and inappropriate offering of solid foods (41). That is why children aged under 3 years are most at risk for stunting, which may be associated with increased risk of being overweight in later life (32).

The study also noted that maternal education status was strongly associated with the co-existence of overweight/obesity and stunting in the final model. The odd of the co-existence of overweight/obesity and stunting among children belonging to noneducated mothers was 4.98 times higher than that of children belonging to educated mothers. This result is in agreement with a study conducted in Cameroon (30), china (42) and Guatemala cited in Kosaka and Umezaki, 2017 (43). This might be because women are often considered as primary caregivers (44) and therefore lack of knowledge and certain attitudinal factors by the mother could eventually influence nutritional status of children through feeding practices (45). Having formal education also enables mothers to take better care, better utilization of the health services, and also to implement better hygiene practice of their child (46).

The other factor which is significantly associated with the co-existence of overweight/obesity and stunting in the final model is maternal age during birth of the child. Children whose mother had maternal age $\geq 28$ during birth were $78 \%$ less likely to experience the co-existence of overweight/obesity and stunting compared to mothers aged $<28$ during birth. This result is in agreement with a study conducted in Cameroon (30). It is also supported by a finding from Mexico (29). The possible explanation for this could be young maternal age during pregnancy is correlated with shorter newborn birth length and small for gestational age delivery (47).

In the final model, children of 3rd and above birth order were 6.38 times more likely to be affected by the co-existence of overweight/obesity and stunting compared to children of 1st birth order. This is supported by studies conducted in Bangladesh (48) and Sub Saharan Africa in 18 countries (49). This is because children born later are vulnerable to sub-optimal nutrition and health outcomes (50). The other explanation could be that as the number of births rises, the food and resources allocated to family members in a household decreases. Therefore, births of higher order might be affected by malnutrition and other health problems (48).

\section{Study limitations}

The study was a facility based and as a result prevents generalization to all under five children living in Ethiopia. In addition to this, the study did not assess variables which could be potentially linked to the co-existence of overweight/obesity and stunting such as children's physical activity, dietary diversity, maternal height and weight. Moreover, the study was also subjected to recall bias since some of the variables were dependent on the memory of mothers and might lead to recall bias.

\section{Conclusion}

The study revealed that the magnitude of the co-existence of overweight/obesity and stunting among under-five children in Addis Ababa was low. In addition to this, child age, maternal education, birth order of the child and maternal age during birth were found to be significantly associated with the co-existence of overweight/obesity and stunting. Therefore, access to formal education for females should be improved. Maternal health programs should also emphasize on improving service uptake and quality of family planning services to delay early pregnancy and reduce the number of high birth order pregnancies. Further research using

Page $10 / 14$ 
longitudinal study design and large sample size are also needed to understand the real contributors of the co-existence of overweight/obesity and stunting.

\section{Declarations}

\section{Ethical Approval}

Ethical approval were obtained from Ethical review committee of Kotebe metropolitan University, Menelik II Medical and Health Science College and Addis Ababa public health Research and Emergency management directorate After the research proposal was duly reviewed by Addis Ababa health Bureau IRB.The researchers were informed with copy of letter to report any change in the study procedure and submit an activity progress report to the Ethical commute as required. Then permission letter were obtain from Addis Ababa education Bureau and selected primary school. Written consent were obtained from selected student's parent, after clearly informed about; the purpose of the study. Parents were inform they could withdraw from the participation at any time. Privacy and confidentiality of information taken from respondent keep properly and names was not record.

\section{Consent}

Consent for publication of the manuscript was not applicable due to the fact that there were no participant's individual data, videos, or images. The data collectors obtained written informed consent from all participants.

\section{Conflicts of Interest}

The authors declare that they have no conflicts of interest.

Availability of data and materials: all data are available as a supplementary file

Consent for publication- Not applicable

\section{Authors' Contributions}

Alem Sebesbie designed the study, carried out the data collection and analysis, and drafted the manuscript. Abebe Minda and Sindew Ahmed were involved in the design of the study, collection, and analyses of data as well as drafting the manuscript. All authors checked and revised subsequent drafts of the manuscript and approved the final version.

\section{Acknowledgments}

We would like to thank Addis Ababa City Health Bureau for providing necessary information required to conduct the study. We would also like to acknowledge our data collectors, supervisors and study participants for their active involvement during the study. Our special thanks also go to staffs and managers of Kirkos Sub City Health Office for their encouragement and material support.

\section{References}

1. World Health Organization (WHO). Double-duty actions for nutrition: Policy Brief [Internet]. Geneva: World Health Organization; 2017. Available from: https://apps.who.int/iris/bitstream/handle/10665/255414/WHO-NMH-NHD-17.2-eng.pdf. Accessed February 20, 2021.

2. Development Initiatives Poverty Research Ltd. Global Nutrition Report: Action on equity to end malnutrition [Internet]. 2020. Available from: https://globalnutritionreport.org/documents/566/2020_Global_Nutrition_Report_2hrssKo.pdf. Accessed February 1, 2021.

3. Sight and Life. Double Burden of Malnutrition at the Individual Level:The frequent co-occurrence of undernutrition and nutrition-related cardiometabolic risk [Internet]. 2018. 76-81 p. Available from: https://sightandlife.org/wpcontent/uploads/2018/12/16_SALMZ_0218_Perspectives_03.pdf. Accessed February 20, 2021 
4. World Bank. The Doble Burden Of Malnutrition in Indonesia [Internet]. 2013. Available from: https://openknowledge.worldbank.org/handle/10986/17007. Accessed February 20,2021.

5. Varela-silva MI, Dickinson F, Wilson H, Azcorra H, Griffiths PL, Bogin B. The Nutritional Dual-Burden in Developing Countries How is it Assessed and What Are the Health Implications? Coll Antropol. 2012;36:39-45.

6. Tzioumis E, Adair LS. Childhood dual burden of under- and overnutrition in low- and middle-income countries: A critical review. 2014;35(2):230-43.

7. World Health Organization (WHO). The doble burden of malnutrition:Policy Brief [Internet]. 2017. Available from: https://www.who.int/publications-detail-redirect/WHO-NMH-NHD-17.3. Accessed February 20, 2021.

8. Tzioumis E, Kay MC, Bentley ME, Adair LS. Prevalence and trends in the childhood dual burden of malnutrition in low- and middle-income countries, 1990 - 2012. Public Health Nutr. 2016;19(8):1375-88.

9. Alamu EO, Eyinla TE, Sanusi RA, Maziya-dixon B. Double Burden of Malnutrition: Evidence from a Selected Nigerian Population. J Nutr Metab. 2020;2020:6.

10. Lerm BR, Crochemore-silva I, Costa JC, Victora CG. The double burden of malnutrition in under-five children at national and individual levels: observed and expected prevalence in ninety-three low- and middle-income countries. Public Health Nutr. 2020;1-8.

11. Popkin BM, Corvalan C, Grummer-Strawn L. Dynamics of the Double Burden of Malnutrition and the Changing Nutrition Reality. Lancet. 2020;395(10217):65-74.

12. Development Initiatives Poverty Research Ltd. Global Nutrition Report:Shining a light to spur action on nutrition [Internet]. 2018. Available from: https://scalingupnutrition.org/news/the-2018-global-nutrition-report-shining-a-light-to-spur-action-onnutrition/. Accessed in March 7, 2021.

13. Fongar A, Gödecke T, Qaim M. Various forms of double burden of malnutrition problems exist in rural Kenya. BMC Public Health. 2019;1-9.

14. World Bank. The Double Burden of Malnutrition: A Review of Global Evidence [Internet]. 2012. Available from: https://documents1.worldbank.org/curated/en/905651468339879888/pdf/795250WPODoubl00Box037737900PUBLIC0.pdf. Accessed in February 20, 2021.

15. Pomati M, Cecilia DM, Larco RMC, Fernandez G, Nandy S, Miranda JJ, et al. Trends and patterns of the double burden of malnutrition (DBM) in Peru: a pooled analysis of 129, 159 mother - child dyads. Int J Obes [Internet]. 2021;609-18. Available from: http://dx.doi.org/10.1038/s41366-020-00725-x

16. Onyango AW, Jean-Baptise J, Samburu B, Mahlangu TLM. Regional Overview on the Double Burden of Malnutrition and Examples of Program and Policy Responses: African Region [Internet]. 2019. Available from: https://www.researchgate.net/publication/337381766_Regional_Overview_on_the_Double_Burden_of_Malnutrition_and_ Examples_of_Program_and_Policy_Responses_African_Region. Accessed February 22, 2021.

17. Farah AM, Nour TY, Endris BS, Gebreyesus SH. Concurrence of stunting and overweight / obesity among children : Evidence from Ethiopia. PLoS One [Internet]. 2021;1-17. Available from: http://dx.doi.org/10.1371/journal.pone.0245456

18. Federal Governmrnt of Ethiopia. NATIONAL NUTRITION PROGRAM, 2016-2020 [Internet]. 2020. Available from: https://www.scribd.com/document/522127483/NNP-II-2016-2020. Accessed November, 20201.

19. Kidane W, Facha W, Negash K. Prevalence and Predictors of Stunting among Children of Age Between 6 to 23 Months in Four Districts of Wolaita Zone, Southern Ethiopia. iMedPub Journals. 2020;(5):1-7.

20. Bogale B, Gutema BT, Chisha Y. Prevalence of Stunting and Its Associated Factors among Children of 6 - 59 Months in Arba Minch Health and Demographic Surveillance Site (HDSS), Southern Ethiopia: A Community-Based Cross-Sectional Study. 2020;2020.

21. Hirvonen K, Baye K, Brauw AD, Abate G. Household food consumption patterns in Addis Ababa, Ethiopia. ResearchGate. 2020; (March).

22. Weldearegay HG, Gebrehiwot TG, Abrha MW. Overweight and obesity among children under five in Ethiopia: further analysis of 2016 national demographic health survey : a case control study. BMC Res Notes [Internet]. 2019;1-6. Available from: https://doi.org/10.1186/s13104-019-4752-8

Page $12 / 14$ 
23. Addis Ababa City Administration. Food Security and Vulnerability in Addis Ababa,Ethiopia [Internet]. 2009. Available from: https://documents.wfp.org/stellent/groups/public/documents/ena/wfp221386.pdf. Accessed February, 2021.

24. Berhane HY, Jirström M, Abdelmenan S, Berhane Y. Social Stratification, Diet Diversity and Malnutrition among Preschoolers: A Survey of Addis Ababa, Ethiopia. MDPI. 2020;

25. World Population Review [Internet]. 2020 [cited 2021 Mar 14]. Available from: https://worldpopulationreview.com/worldcities/addis-ababa-population

26. Hien NN, Hoa NN. Nutritional Status and Determinants of Malnutrition in Children under Three Years of Age in Nghean, Vietnam. ResearchGate. 2009;

27. Jones AD, Hoey L, Blesh J, Janda K, Llanque R. Peri-Urban, but Not Urban, Residence in Bolivia Is Associated with Higher Odds of Co-Occurrence of Overweight and Anemia among Young Children, and of Households with an Overweight Woman and Stunted Child. 2018;

28. Atsu BK, Guure C, Laar AK. Determinants of overweight with concurrent stunting among Ghanaian children. 2017;1-12.

29. Fernald LC, Neufeld LM. Overweight with concurrent stunting in very young children from rural Mexico: prevalence and associated factors. 2007;623-32.

30. Rihlat SM, Allirot X, Pasquet P. Determinants of overweight associated with stunting in preschool children of Yaoundé,. ResearchGate. 2009;(March).

31. Rachmi CN, Agho KE, Li M, Baur LA. Stunting coexisting with overweight in $2 \cdot 0$ - 4 - 9-year-old Indonesian children: prevalence, trends and associated risk factors from repeated cross-sectional surveys. 2016;19(15):2698-707.

32. Mamabolo RL, Alberts M, Steyn NP, Waal HAD De, Levitt NS. Prevalence and determinants of stunting and overweight in 3year-old black South African children residing in the Central Region of Limpopo Province, South Africa. 2005;8(5):501-8.

33. Center for Disease Control (CDC). National Health and Nutrition Examination Survey(NHANES): Anthropometry Procedures Manual [Internet]. 2007. Available from: https://www.cdc.gov/nchs/data/nhanes/nhanes_07_08/manual_an.pdf. Accessed February, 2021.

34. Central Statistical Agency(CSA) and ICF. Ethiopia Demographic and Health Survey 2016 [Internet]. Addis Ababa, Ethiopia, and Rockville, Maryland, USA; 2016. Available from: https://dhsprogram.com/pubs/pdf/FR328/FR328.pdf. Accessed February, 2021.

35. Kukka A. Prevalence of Double Burden of Malnutrition among Indian Pre-School Children: an Analysis of Cross-Sectional DLHS-4 Data from 23 States. 2018;

36. Do LM, Lissner L, Ascher H. Overweight, stunting, and concurrent overweight and stunting observed over 3 years in Vietnamese children. Glob Health Action [Internet]. 2018;11(1). Available from: https://doi.org/10.1080/16549716.2018.1517932

37. Okubo T, Blankenship JL. Risk factors modifying the double burden of malnutrition of young children in Thailand. 2020;16(July 2019):1-9.

38. Forero AY, Garcia J, Sarmiento OL, Parra DC, Gonz SA. The dual burden of malnutrition in Colombia 1-4. 2014;100(1):162835.

39. Amoo TB. The Double Burden of Malnutrition Across the Lifecourse. Lupine Online J Med Sci. 2019;327-30.

40. Hall J, Walton M, Ogtrop F Van, Guest D, Black K, Beardsley J. Factors influencing undernutrition among children under 5 years from growing communities in Bougainville. BMJ Glob Heal. 2020;1-10.

41. Black RE, Victora CG, Walker SP, Bhutta ZA, Christian P, Onis M De, et al. Maternal and Child Nutrition 1 Maternal and child undernutrition and overweight in low-income and middle-income countries. 2011;

42. Zhang N, Bécares L, Chandola T. Patterns and Determinants of Double-Burden of Malnutrition among Rural Children: Evidence from China. 2016;1-19.

43. Kosaka S, Umezaki M. A systematic review of the prevalence and predictors of the double burden of malnutrition within households. 2017;1118-27.

44. Id MB, Id FA, Amporfro DA, Abada LA. The epidemiology of undernutrition and its determinants in children under five years in Ghana. 2019;1-23. 
45. Mahmudiono T, Segalita C. Socio-Ecological Model of Correlates of Double Burden of Malnutrition in Developing Countries: A Narrative Review. 2019;(Ci).

46. Sarma H, Khan JR, Asaduzzaman M, Uddin F, Tarannum S, Hasan M. Factors Influencing the Prevalence of Stunting Among Children Aged Below Five Years in Bangladesh. 2017;38(3):291-301.

47. Workicho A, Belachew T, Argaw A, Ghosh S, Kershaw M, Lachat C, et al. Maternal nutritional status mediates the association between maternal age and birth outcomes. 2020;(April 2019):1-8.

48. Rahman M. Association between order of birth and chronic malnutrition of children: a study of nationally representative Bangladeshi sample. Artig Artic. 2016;1-12.

49. Howell EM, Holla N, Waidmann T. Being the younger child in a large African Family: a study of birth order as a risk factor for poor health using the demographic and health surveys for 18 countries. BMC Nutr [Internet]. 2016;1-12. Available from: http://dx.doi.org/10.1186/s40795-016-0100-8

50. Huey SL, Finkelstein JL, Venkatramanan S, Udipi SA, Ghugre P, Thakker V, et al. Prevalence and Correlates of Undernutrition in Young Children Living in Urban Slums of Mumbai, India : A Cross Sectional Study. 2019;7(July):1-13.

\section{Figures}

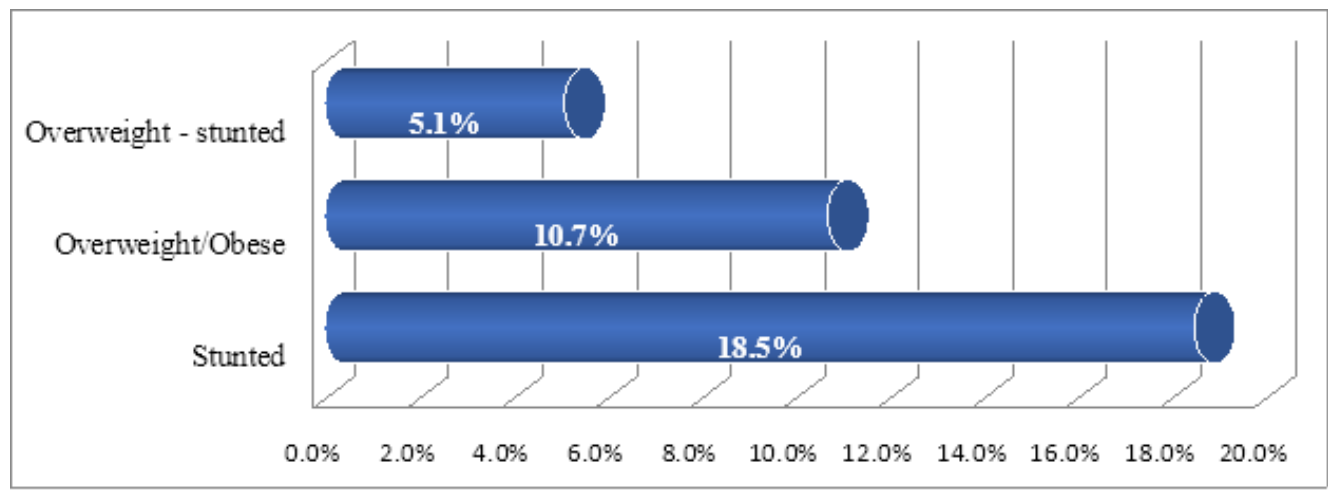

Figure 1

Magnitude of the co-existence of overweight/obesity and stunting among under-five children in Addis Ababa, Ethiopia, 2021

\section{Supplementary Files}

This is a list of supplementary files associated with this preprint. Click to download.

- Alemdata2021.xlsx 